\title{
Membrane Adsorption Characteristics Determine the Kinetics of Flow-Through Transductions
}

\author{
Alice S. Chuck* and Bernhard Ø. Palsson $†$ \\ Department of Chemical Engineering, University of Michigan, Ann Arbor, \\ Michigan 48109
}

Received August 31, 1995/Accepted February 8, 1996

Retrovirus-mediated gene transfer is currently limited by random Brownian motion of the retrovirus. This limitation can be overcome by flowing the retrovirus solution through a porous membrane that supports the target cells, leading to a significant increase in the transduction efficiency. This procedure is termed "flow-through transduction." In this study, we characterized the effects of the fluid flowrate and the influence that membrane characteristics have on the flow-through transduction procedure. The transduction efficiencies increased with flowrate until a plateau was reached at average flow velocities exceeding $0.3 \mathrm{~cm} / \mathrm{h}$ for flow times of 3 to $4 \mathrm{~h}$, using a collagencoated depth (COL) membrane. A correlation between the optimal time for maximal gene transfer using flowthrough transductions and the optimal time for maximal virus activity on the membrane was found, suggesting that the membrane adsorption capacity for virus determined the amount of gene transfer that could occur.

Membrane adsorption characteristics were further investigated using two different membrane types: a tracketched polyester screen (PE) membrane and the COL membrane. Flow-through transductions using the PE and COL membranes showed that a high level of gene transfer could be attained using the COL membrane while the PE membrane gave much lower transduction efficiencies. The addition of the polycation polybrene (PB) changed these results markedly, making transductions achieved on the PE membrane similar in number to those obtained on the COL membrane. Since PB is believed to influence the virus adsorption to $P E$ membrane, these results further support the conclusion that the increase in gene transfer achieved by the flow-through transduction procedure is due to virus adsorption to the membrane. The flow-through transduction procedure thus leads to colocalization of the viral vector and the target cell that in turn leads to a high transduction efficiency. (c) 1996 John Wiley \& Sons, Inc.

Key words: retrovirus • gene therapy - gene transfer • virus adsorption - membranes

\section{INTRODUCTION}

Biological vectors, such as retroviruses, adenoviruses, and adeno-associated viruses are generally used for gene transfer in gene therapy, where stable and efficient gene

\footnotetext{
* Present address: Amgen, Inc., 1840 DeHavilland Dr., Thousand Oaks, CA 91320.

$\dagger$ To whom all correspondence should be addressed at (present address): Department of Bioengineering, University of California at San Digeo, La Jolla, CA 92093-0412. E-mail: bpalsson@bioeng.ucsd.edu.
}

transduction must take place to specific target cells. ${ }^{1,8,23}$ For a virus to gain entry, and thus deliver its gene into the cell, it must first encounter and then bind via its surface proteins (viral attachment proteins) to receptors on the target cell. ${ }^{13,20,28}$ It has been suggested that multiple receptors or attachment sites are responsible for the virus adsorbing onto and ultimately gaining entry into the cell. ${ }^{13}$ Initial binding of virions to cells is often nonspecific, where glycoproteins on the virus surface can bind weakly to glycoprotein, proteoglycan, or integrin protein receptors commonly displayed on cell surfaces. ${ }^{13,14,21}$

Retrovirus-mediated gene transfer is typically carried out using static transduction protocols, in which a liquid layer containing the retrovirus is placed on top of a bed of target cells. The physics of this transduction system may be described by three processes occurring simultaneously (Fig. 1): (1) Brownian motion of the retrovirus; (2) decay of the retrovirus; and (3) adsorption, or capture, of the retrovirus by the target cell. A retrovirus is a colloidal particle with a density similar to that of tissue culture medium, 1.16 to $1.18 \mathrm{~g} / \mathrm{mL}$. $^{18}$ Its root mean square displacement $(l)$ by Brownian motion over time $(t)$ can be described by ${ }^{12}$ :

$$
l=\sqrt{2 D t}
$$

where $D$ is the diffusion coefficient. The numerical value of the diffusion constant for a retrovirus can be estimated from the Stokes-Einstein equation (e.g., ref. 9) to be approximately $6.5 \times 10^{-8} \mathrm{~cm}^{2} / \mathrm{s}$ using a viral diameter of $100 \mathrm{~nm} .{ }^{11}$

Retroviral half-lives $\left(t_{0.5}\right)$ are generally short. ${ }^{15-17,24,25}$ We have measured the half-life for a murine amphotropic retrovirus produced by the $\psi$ CRIP cell line ${ }^{10}$ to be about 5 to $8 \mathrm{~h}$ at $37^{\circ} \mathrm{C} .{ }^{5}$ Using the appropriate numerical values for the diffusion coefficient and half-life in Eq. (1), we estimate the distance that an average retroviral particle can travel within one half-life $\left(l_{0.5}\right)$ to be 480 to $610 \mu \mathrm{m}$. Since tissue culture procedures typically use liquid depths of 2 to $5 \mathrm{~mm}$, the majority of retroviruses in the transduction medium above a level of 480 to $610 \mu \mathrm{m}$ will not be able to reach the cell bed within one half-life. Only those particles closest to the target cells will be captured efficiently and within the time span of 


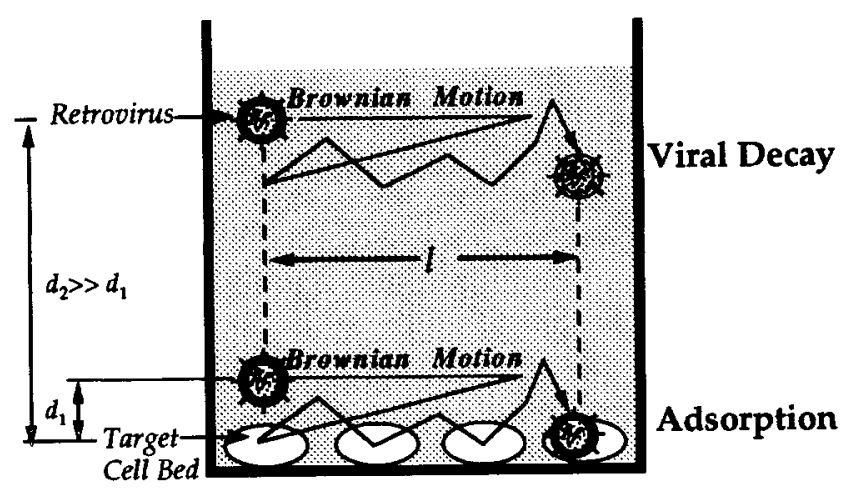

Figure 1. Static transduction: physical processes. This schematic shows how a retrovirus' distance from the target cell bed affects the probability of it being adsorbed. The virus close to the bed, at $d_{1}$, has a high probability of being adsorbed, whereas the virus further away, at $d_{2}$, decays over the same time period and thus cannot reach a target cell. Each retrovirus travels an average distance $l$ by Brownian motion over the time period of interest.

the retroviral half-life. We have shown that retroviruses within $500 \mu \mathrm{m}$ of the target cell bed were able to deliver the gene, while viruses further away did not contribute to cell transduction. ${ }^{5}$

The importance of distance between the virus particle and target is depicted in Figure 1, which shows a retrovirus particle's Brownian motion close to the target cell bed $\left(d_{1}\right)$ and far from the target cell bed $\left(d_{2}\right)$. The retroviruses close to the target bed are able to strike it many times, greatly increasing the chance of being captured by a target cell receptor. The retroviruses far away from the target may travel the same mean distance $(l)$, but decay before being adsorbed by the target cells. Thus, by relying on Brownian motion to deliver the retrovirus to the target cell, as in static transductions, the rate of virus delivery is in large part determined by the proximity of the available viruses to the target cell, and the time in which the majority of viruses are still active (the half-life). Under these diffusional constraints, the number of virions reaching the cell bed can be increased by increasing the number of retroviruses per unit volume in the transduction solution. However, high retroviral titers have proven difficult to obtain, $, 3,4,19$ and short retroviral half-lives compound the problem of inefficient gene transfer to the target cell bed. This limitation can be overcome by flowing the retrovirus solution through a porous membrane that supports the target cells, leading to significant increases in transduction efficiencies. This procedure was termed "flow-through transduction." 5

The factors governing flow-through transduction are characterized here. Using this method of gene transfer, the frequency of viral encounter with the target cell is expected to depend on the flowrate of virus solution through the supporting membrane. Furthermore, the amount of virus retained on the membrane is expected to depend on both the capacity of the porous membrane substrate and the number and type of target cells. To address these issues, two types of membranes were used as porous supports for the target cells: screen membranes and depth membranes. With screen membranes, particle capture takes place on the membrane surface. With depth membranes, particle capture occurs by random entrapment within the membrane's tortuous pores (i.e., both on the membrane surface and within the membrane's depth). The two membranes used in this work were the tissue-culture treated polyester screen-type membrane, and the collagen-coated Teflon depth-type membrane.

The success of all flow-through transductions was measured against static transductions (where the virus solution does not flow), using the same transduction materials: target cell inoculum and retrovirus solution. Retrovirus solution typically contains polycations, such as polybrene, because it has been observed that static retroviral transductions can take place much more efficiently in the presence of a polycation. ${ }^{67}$ Polybrene is believed to act to reduce electrostatic repulsion between the negatively charged bilipid layers on the virus and the target cell., ${ }^{2,6}$ An optimal polybrene concentration of $4 \mu \mathrm{g} / \mathrm{mL}$ has been reported for virus binding to a variety of cell lines. ${ }^{6}$ The presence (or absence) of polybrene is expected to affect the performance of the two types of membranes differently, since the screen membrane is negatively charged and the depth membrane is uncharged.

Detailed characterization of the flow-through transduction procedure is lacking. Therefore, this study was undertaken to address three questions, of which the answers would lead to a deeper understanding of how the flow-through procedure works: (1) What flow velocities are sufficient to overcome the limitations imposed by Brownian motion? (2) How well does the porous membrane retain the virus flowed? (3) What is the effect of different membrane substrates on number of flowthrough transductions obtained?

\section{MATERIALS AND METHODS}

\section{Cell Culture}

$\mathrm{NIH} / 3 \mathrm{~T} 3$ and $\mathrm{CV}-1$ cells were used as model target cell lines for these experiments. NIH/3T3 is a mouse fibroblast cell line (ATCC CRL 1658), and CV-1 is a primate cell line (derived from an African green monkey kidney, ATCC CCL 70). Target cells were seeded at 3000 cells $/ \mathrm{cm}^{2}$ in either six-well plates (Costar, Cambridge, MA) or tissue culture membranes 1 day prior to transduction (unless otherwise stated). Collagen-coated membranes (Transwell-COL ${ }^{\mathrm{TM}}$ cell culture inserts from Costar) and polyester membranes (Transwellclear $^{\mathrm{TM}}$ cell culture inserts from Costar) were used. The Transwell-COL ${ }^{\mathrm{TM}}$ membranes are of the depth (filter) 
membrane type, and the Transwell-clear ${ }^{\mathrm{TM}}$ membranes are of the screen membrane type. They both had a pore size rating of $0.4 \mu \mathrm{m}$ and a diameter of $24.5 \mathrm{~mm}$ (giving a membrane cross-sectional area of $4.71 \mathrm{~cm}^{2}$ ). The estimated porosity of the Transwell-COL ${ }^{\mathrm{TM}}$ membrane was $50 \%$ to $60 \%$, and the pore density of the Transwellclear $^{\mathrm{TM}}$ membrane was $4 \times 10^{6}$ pores $/ \mathrm{cm}^{2}$. The Transwell-COL ${ }^{\mathrm{TM}}$ was of a neutral charge, and the Transwellclear $^{\mathrm{TM}}$ was tissue culture treated with a negative charge.

The morphology of the target cells depended on the attachment substrate: both $\mathrm{CV}-1$ and NIH/3T3 target cells tended to grow along striations on the Transwell$\mathrm{COL}^{\mathrm{TM}}$ membranes, and both were of more rounded shape when grown on Transwell-clear ${ }^{\mathrm{rM}}$ membranes compared to tissue culture plastic. The replicationdefective retrovirus producer cell line used was kindly provided by Dr. James Wilson at the University of Michigan (construction of a similar vector is described in ref. 29) and was made by transfecting a pMFG vector containing a lac $Z$ gene into $\psi \mathrm{CRIP} .{ }^{10}$ The retroviruses yielded from the producer cell line belonged to the Murine Leukemia Virus (MuLV) family. The producer cells were thawed every 6 weeks and cultured in 10$\mathrm{mL}$ tissue culture dishes (Falcon ${ }^{\mathrm{TM}}$, Becton Dickinson, Franklin Lakes, NJ). All cell lines were grown with $10 \%$ calf serum supplement (Gibco, Grand Island, NY) in DMEM at $37^{\circ} \mathrm{C}$ and $5 \% \mathrm{CO}_{2}$.

\section{Retrovirus Supernatant}

Medium that was conditioned for $24 \mathrm{~h}$ by a confluent monolayer of producer cells was filtered through $0.4 \mu \mathrm{m}$ pore-sized filters (low protein binding Sterile Acrodisc $^{\mathrm{TM}}$, Gelman, Ann Arbor, MI). Virus medium harvested from producer cell cultures was assigned a relative retroviral concentration value of 1.0. This rather arbitrary assignment was necessary due to the batchto-batch variation of retroviral titer that occurs with producer cell lines, ${ }^{22,24}$ where the virus productivity of a producer cell declines with each succeeding passage. Variable retroviral concentrations were made by diluting the virus supernatant with growth medium. A relative retroviral concentration of 0.1 was used for infecting cultures that would later be assayed (for lac $Z$ expression) by $\mathrm{X}$-gal staining. Similarly, viral concentrations of 0.5 were used for infecting cultures that would be assayed by flow cytometry. Polybrene (Aldrich, Milwau$\mathrm{kee}, \mathrm{WI}$ ) was added to $4 \mu \mathrm{g} / \mathrm{mL}$ (unless otherwise stated). Negative controls (mock infections) were prepared by adding polybrene (at the same levels as in the virus supernatant) to growth medium. These controls were carried out using both the static and flow-through transduction procedures.

\section{Static Transduction}

Static transductions were carried out on cell culture inserts in parallel with flow-through transductions, unless stated otherwise. The substrates used in this work (i.e., tissue culture plastic, Transwell-COL ${ }^{\mathrm{TM}}$, or Transwell-clear ${ }^{\mathrm{TM}}$ ) did not affect either cell growth or (static) transduction efficiency. ${ }^{5}$ Static transductions were carried out as follows: medium was removed from target cell cultures and replaced by $2 \mathrm{~mL}$ of virus solution. A schematic is shown in Figure 2A. The cultures were then incubated for the determined transduction time, after which the retrovirus solution was removed and fresh growth medium was added. Cultures were assayed for $l a c Z$ gene expression 3 to 4 days later.

\section{Flow-Through Transductions}

Virus medium was gravity flowed through the seeded collagen or polyester membranes at an average flow velocity of $\sim 0.2 \mathrm{~cm} / \mathrm{h}$ (flow velocities ranged from $\sim 0.1$ to $0.3 \mathrm{~cm} / \mathrm{h}$ for the collagen membranes and $\sim 0.1$ to $0.2 \mathrm{~mL} / \mathrm{h}$ for the polyester membranes) for the transduction period (up to $10 \mathrm{~h}$ ) at $37^{\circ} \mathrm{C}$. A schematic is shown

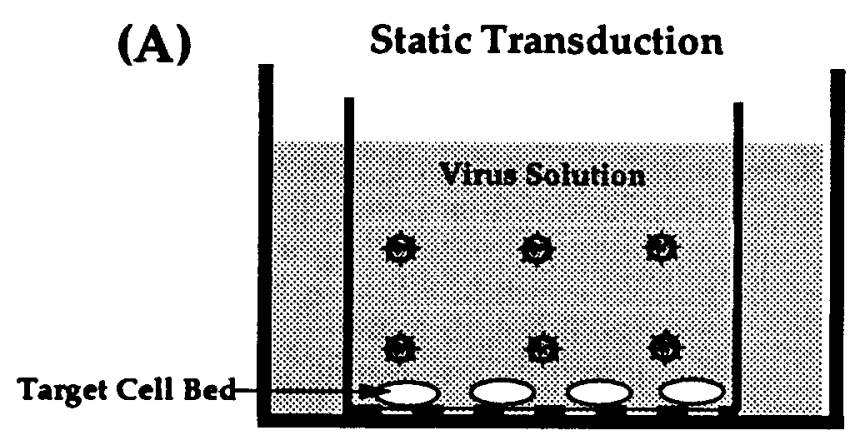

(B) Flow-Through Transduction

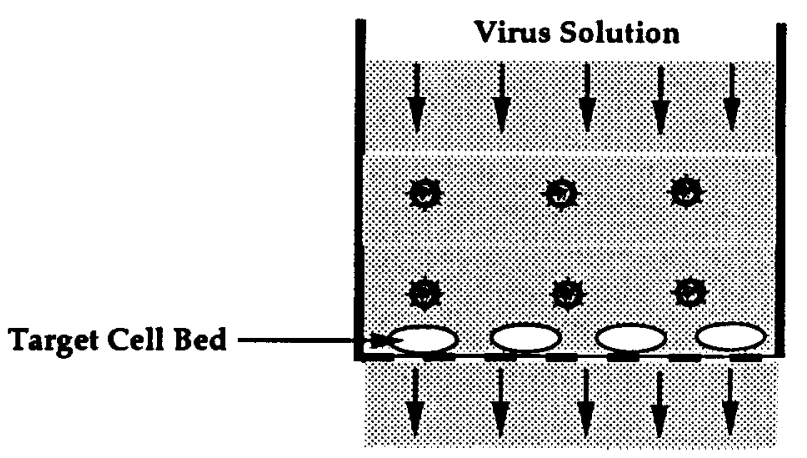

Figure 2. Static transduction vs. flow-through transduction. In static transduction (A), virus solution overlays a bed of target cells for the transduction period. In flow-through transduction (B), virus solution flows through the target cell bed for the duration of the transduction period. Flow-through transductions were always carried out in parallel with static transductions, using the same preparation of virus solution and the same target cell density. 
in Figure 2B. After the transduction period, the virus medium was removed from the reservoir above the target cell bed and fresh growth medium was added. Cultures were left to incubate (without media flow) for 3 to 4 days until the time of assay.

\section{Controlled Flowrate Transduction}

Seeded cell culture inserts were fitted into polycarbonate housings and Harvard Apparatus (South Natick, MA) syringe pumps were used to provide a steady and controlled flow of virus solution through the membranes for 3 to $4 \mathrm{~h}$. Average flow velocities were calculated by dividing the volumetric flowrate by the membrane crosssectional area, i.e., $4.71 \mathrm{~cm}^{2}$. A photograph of this setup is shown in Figure 3A and B. After the transduction period, the inserts were removed from the housings, the remaining fluid in the inserts was washed and replaced with fresh growth medium, and the cultures were left to incubate in static mode at $37^{\circ} \mathrm{C}$ for 3 to 4 days until flow cytometry was used to measure lac $Z$ expression.

\section{Virus Loading Experiments}

Virus solution was flowed through membranes without target cells over the designated loading times. At each time-point, flow was stopped in two inserts, the virus solution was removed, and $2 \mathrm{~mL}$ of target cell solution at $7.5 \times 10^{3}$ cells $/ \mathrm{mL}$ with polybrene (at $4.4 \mu \mathrm{g} / \mathrm{ml}$ ) was added to the membrane. (Note that the target cells had no contact with virus until after the flow period.) The target cell medium was removed 12 to $24 \mathrm{~h}$ later and replaced with $2 \mathrm{~mL}$ of fresh medium. Viral activity on

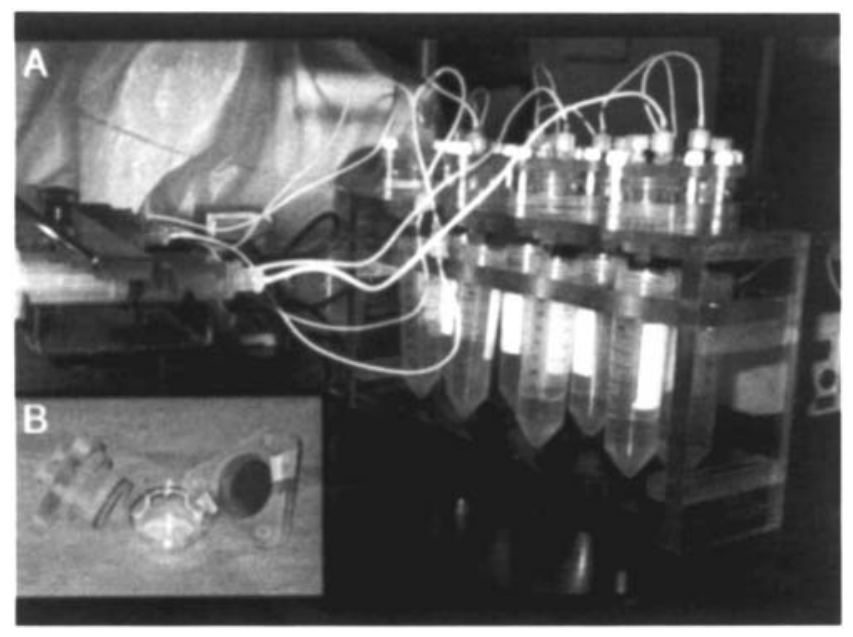

Figure 3. Controlled flowrate transduction setup. (A) Polycarbonate membrane housings for the cell culture inserts were connected to syringes containing transduction fluid. The fluid flowrates were controlled with Harvard Apparatus syringe pumps. (B) A photograph of a cell culture insert and an unassembled membrane housing. Transwell$\mathrm{COL}^{\mathrm{TM}}$ inserts were used with $0.4 \mu \mathrm{m}$ rated pore diameter. the membrane was indicated by transduction efficiency, which was measured by flow cytometry 3 to 4 days later. In these virus loading experiments, the virus activities are measured immediately after the indicated loading times. The percentage of cells transduced measured here is different from the percentage when target cells were present throughout the flow period. In the first case, the percentage indicates the virus activity on the membrane just after the loading time. In the second case, the percentage represents the cumulative number of cells transduced throughout the loading time (as in flow-through transduction).

\section{LacZ Expression Assay (X-Gal Staining)}

Gene transfer was measured by $\operatorname{lac} Z$ expression, or $\beta$-galactosidase production. $\beta$-Galactosidase reacts with X-gal (5-bromo-4-chloro-3-indoyl- $\beta$-D-galactoside; Sigma) to form a blue dye product which turns the cell carrying the gene blue (thus designating the cell as being transduced). First, each cell culture well was washed twice with $2 \mathrm{~mL}$ of Hanks buffered saline solution (HBSS, Gibco) and then fixed with $1.5 \mathrm{~mL}$ of $2 \%(\mathrm{v} / \mathrm{v})$ formaldehyde (Sigma) and $0.2 \%$ (v/v) glutaraldehyde (Sigma) for $5 \mathrm{~min}$. Following fixation, the cells were washed once more in HBSS before adding $1.5 \mathrm{ml}$ of staining solution. The staining solution consisted of $50 \mu \mathrm{L}$ of $[20 \mathrm{mg} / \mathrm{mL}$ X-Gal powder dissolved in $N, N$ dimethylformamide (DMF, Sigma)] per milliliter of [ $5 \mathrm{mM} \mathrm{K}_{3} \mathrm{Fe}(\mathrm{CN})_{6}$ (Sigma), $\left.5 \mathrm{mM} \mathrm{K} \mathrm{Ke}_{4} \mathrm{FeN}\right)_{6} \cdot 3 \mathrm{H}_{2} \mathrm{O}$ (Sigma), and $2 \mathrm{mM} \mathrm{MgCl}$ (Sigma) in PBS]. The samples were incubated 1 to 4 days at $37^{\circ} \mathrm{C}$ to allow any blue cell color to develop, and numbers of colony forming units (CFU, at 2 to 8 cells/colony) in each well were counted.

\section{Flow Cytometry}

The product of the transferred gene, $\beta$-galactosidase, reacts with fluorescein di- $\beta$-D-galactopyranoside (FDG) in a way similar to $X-G a l$, to form a product which is detectable using flow cytometry. To determine the percentage of cells transduced, the cells were prepared in the following manner. Each cell culture insert was washed three times with $2 \mathrm{~mL}$ of HBSS and the cells removed by $1 \mathrm{~mL}$ trypsin (Gibco) exposure. Fresh growth medium was then used to resuspend and wash the cells. Reagents from the FluoReporter lac $Z$ gene detection kit from Molecular Probes (Eugene, OR) were used to prepare and stain the cells. The cells were incubated in a $37^{\circ} \mathrm{C}$ water bath for $5 \mathrm{~min}$ and then loaded with substrate by hypotonic shock as follows: $50 \mu \mathrm{L}$ of $2 \mathrm{~m} M$ FDG was added to each tube at $37^{\circ} \mathrm{C}$ and left to incubate for $90 \mathrm{~s}$. The tubes were then immersed in ice, and $450 \mu \mathrm{L}$ of ice-cold PBS with human IgG (Sigma) and $1 \mathrm{mg} / \mathrm{mL}$ propidium iodide (PI) was added. 
A Coulter Epics flow cytometer was used to measure percentage of cells transduced. The following three selection criteria were used to measure this percentage. First, single cells were gated from a 90LS-FALS 2D dot plot and used to create a red (PI) fluorescence histogram. Second, live cells were gated off the PI histogram based on their low PI signal. These live cells were used to create a green (fluorescein) fluorescence histogram. These histograms were usually bimodal, consisting of two peaks: one indicating cells positive for lac $Z$ expression, the other indicating cells negative for lac $Z$ expression. The location of the lower fluorescence peak corresponded to the single peak observed with the autofluorescence (no FDG staining) and the mock transduction controls. The two peak locations did not vary significantly between the biomodal histograms.

The third and final selection was to measure percentage of cells lying above log mean fluroescence channel number 120 . This channel number was chosen as a conservative indicator of positive fluorescence from the bimodal histograms. Percentage of cells transduced was calculated by dividing the area in the positive fluorescence peak by the total log green fluorescence histogram area. Transduction efficiency is denoted by percentage of cells transduced (\% Transduced). All samples were assayed within 6 hours after staining. Replicate samples were run in the latter half of this period, and early samples were rerun at the end. No significant difference in \% Transduced was measured as a function of time of assay.

\section{Scanning Electron Micrograph (SEM)}

A 15- to 20-nm thickness of gold film was sputter coated (Model \#E5100, Polaron Instruments, Hatfield, PA) onto bare, unused membranes, and a $10-\mathrm{kV}$ accelerating voltage was used with a dual-stage scanning electron microscope (International Scientific Instruments, Topcon Model \#DS-130) to obtain the images shown in Figure 8.

\section{RESULTS}

The three stated questions were addressed in three separate sets of experiments. In the first set of experiments, the effect of virus solution flow velocity on the number of cells transduced was measured. In the second set of experiments, the role of virus retention by the target cell bed was characterized. To distinguish the adsorption of the target cells from that of the bare membrane, the virus activity of flow-through effluent (where the membrane was seeded with target cells) was measured and compared with the effluent activity of flow through a membrane bare of target cells. Thus, the adsorption kinetics of the virus to the membrane substrate was measured. In the third set of experiments, the performance of different membrane substrates was compared.
Different levels of the polycation polybrene were also used to examine the retrovirus interaction with the target cell bed. At this point, it should be noted that, due to the batch-to-batch variation in retroviral activity, the percentage of cells transduced varied between identical experiments, such that measurements of transduction efficiencies could not be averaged between experiments. The data shown are respresentative of multiple experiments, and emphasis is placed on the observed trends rather than the values of transduction efficiencies obtained.

\section{Effect of Virus Solution Flowrates}

To determine the optimal flow velocity for the flowthrough transductions, gene transfer was measured as a function of overall flow velocity over a range of 0 to $2 \mathrm{~cm} / \mathrm{h}$ (corresponding to flowrates of 0 to $8 \mathrm{~mL} / \mathrm{h}$ ) for a time period of 3 to $4 \mathrm{~h}$. This range was selected so as not to harm the target cells and to include the rate observed by gravity flow (approximately $0.2 \mathrm{~cm} / \mathrm{h}$ ). Controlled flowrate transductions (see Fig. 3) showed an increase in the number of transduced cells with an increase in the flow velocity. Transwell-COL ${ }^{\mathrm{TM}}$ membranes were used. Typical results are shown in Figure 4 , in which the percentage of cells transduced increased with flow velocity-up to $\sim 0.3 \mathrm{~cm} / \mathrm{h}$, where an apparent plateau occurred. Increasing the transport rate of virus to the target cell bed resulted in no additional cells being transduced beyond the plateau point. The observance of a plateau rather than a peak suggested the target cell bed was saturated or, more generally, that the rate of virus adsorbance became lower than the rate of virus

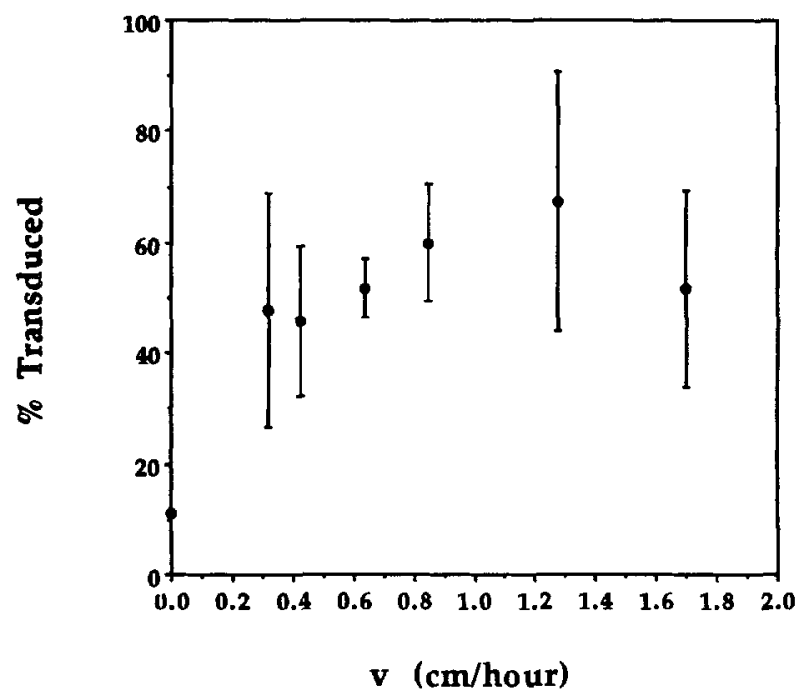

Figure 4. Flow-through transduction as a function of fluid flow velocity. Transduction efficiency ( $\%$ Transduced) as a function of average flow velocity (v) for CV-1 target cells. Transwell-COL ${ }^{\mathrm{TM}}$ membranes were used. Each datapoint represents the average of two independent samples. 
delivery. Therefore, after flowing for $4 \mathrm{~h}$ at more than $0.3 \mathrm{~cm} / \mathrm{h}$, the target cell bed had reached its adsorbance capacity. This adsorbance capacity could generally be reached at very slow flow velocities of less than $0.1 \mathrm{~cm} / \mathrm{h}$, although the percentage of cells transduced (plateau value) depended on the concentration of the virus solution used.

\section{Virus Adsorbance to the Membrane}

To answer the question of what limited virus adsorption, two types of experiments were performed as a function of flow-through time: the first measured the amounts of virus removed by bare membranes compared with seeded membranes, and the second measured the virus activity on a bare membrane.

First, the adsorption of virus by target cells was compared to adsorption of virus by the membrane. The membranes were either seeded or bare of target cells so that the effect of the two possible adsorbers (the membrane and the target cells) could be distinguished.

Because the retrovirus decays with time (according to its half-life) regardless of whether it flows through a membrane, it was necessary to distinguish the virus activity due to removal by the membrane from the decrease in activity due to time. Thus, the effluent activity was compared with the natural decay of the virus, which was measured using virus solution that had not flowed through the membrane. This virus solution was the same age (time after harvest) as the flowed virus. Transwell$\mathrm{COL}^{\mathrm{TM}}$ membranes and CV-1 target cells were used in these experiments. Two observations were apparent from Figure 5. First, the rate of decline in the medium exiting the membrane was much faster than the natural decay rate-a slope of $0.60 \mathrm{~h}^{-1}$ compared to the normal $0.09 \mathrm{~h}^{-1}$ (corresponding to a half-life of $\sim 7.7 \mathrm{~h}$ ) (Fig. 5). The flow-through effluent points at $15 \mathrm{~h}$ do not fall on the line shown, and probably indicate that the membranes were no longer removing virus at the same initial rate. The second observation was that the profiles of the decrease in viral activity after flow through both the seeded and bare membranes were identical, showing that the presence of the target cells did not contribute significantly towards the removal of virus from the flowing solution (i.e., the activity of the medium exiting the membrane) for the low seeding density used. Thus, the adsorbance of virus by the target cells was insignificant compared to the removal, or adsorbance by the membrane.

In the second experiment, the virus activity adsorbed to Transwell-COL ${ }^{\mathrm{TM}}$ membranes was measured over a range of flow times (Fig. 6A). Here, the viruses were deposited onto the membrane over the flow-through time, and did not come into contact with target cells until the end of this flow time, which was designated as the "loading time." In these experiments, the transduction efficiencies of the target cells were used to indicate

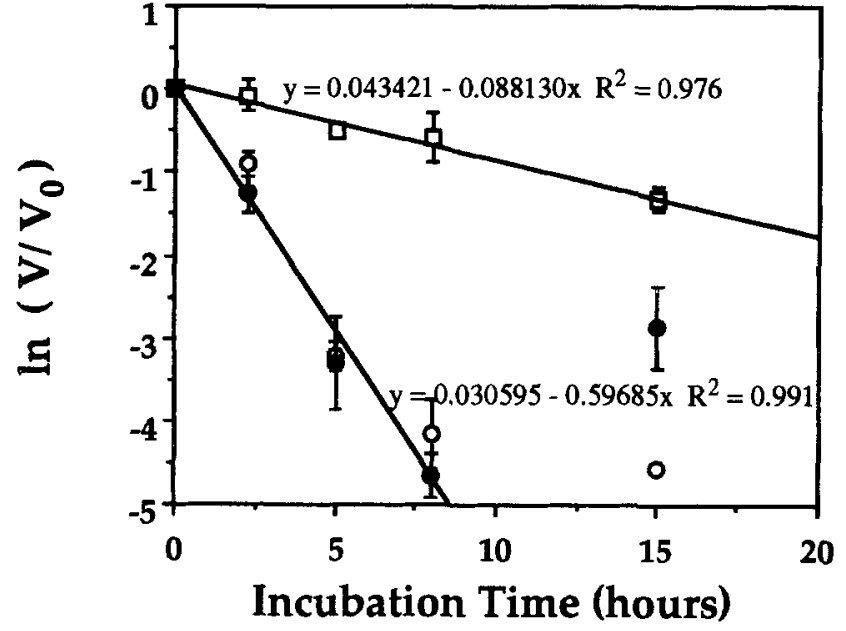

Figure 5. Membrane adsorption of virus during flow-through. Virus activity in the effuent was measured over flow-through time (Incubation Time) at $37^{\circ} \mathrm{C}$ using either bare $(O)$ or seeded $(\Theta)$ Transwell$\mathrm{COL}^{\mathrm{rm}}$ membranes. The seeded membranes were inoculated $24 \mathrm{~h}$ prior to flow-through with $3000 \mathrm{CV}-1$ target cells $/ \mathrm{cm}^{2}$. Effluent was collected from nine membranes of either type approximately every $2.5 \mathrm{~h}$, and the activity (V) was measured in triplicate using X-Gal staining and CV-1 target cells seeded onto tissue culture plates. The initial virus activity is designated $V_{0}$. The normal decay rate of virus that was not flowed through any membrane is also shown $(\square)$. Each datapoint represents the average of three independent measurements, and the standard deviation is represented by the length of the error bars.

the virus activity at the time of loading. In this way, the virus concentration on the membrane as a function of flow time could be distinguished from virus transduction occurring during the flow time (where target cells are present throughout the flow time). This distinction was necessary to determine the significance of the optimal time for the membrane to adsorb virus as compared with that for the target cells to adsorb virus, as in a flow-through transduction. Given the short half-life of retroviruses, the latter option would yield more transductions within the same flow time.

The amount of active virus deposited on the membrane peaked between 2 and $4 \mathrm{~h}$ (Fig. 6A). Characteristic of retroviruses, the viral activity decays within the flow time period also. Before the plateau of 2 to $4 \mathrm{~h}$, the virus activity on the membrane continued to increase due to a higher rate of virus deposition than decay; during this time period, the rate of virus deposition onto the membrane was equal to what decayed on the membrane; after this time period, the virus on the membrane decayed at a faster rate than what was deposited. The decline of virus activity during this third time period corresponded to the natural decay of the virus (Fig. 6B, half-life of $\sim 4.2$ to 4.5 hours), so the membrane was not adsorbing any more virus after the second period. The membrane had reached its adsorption capacity after $4 \mathrm{~h}$. 

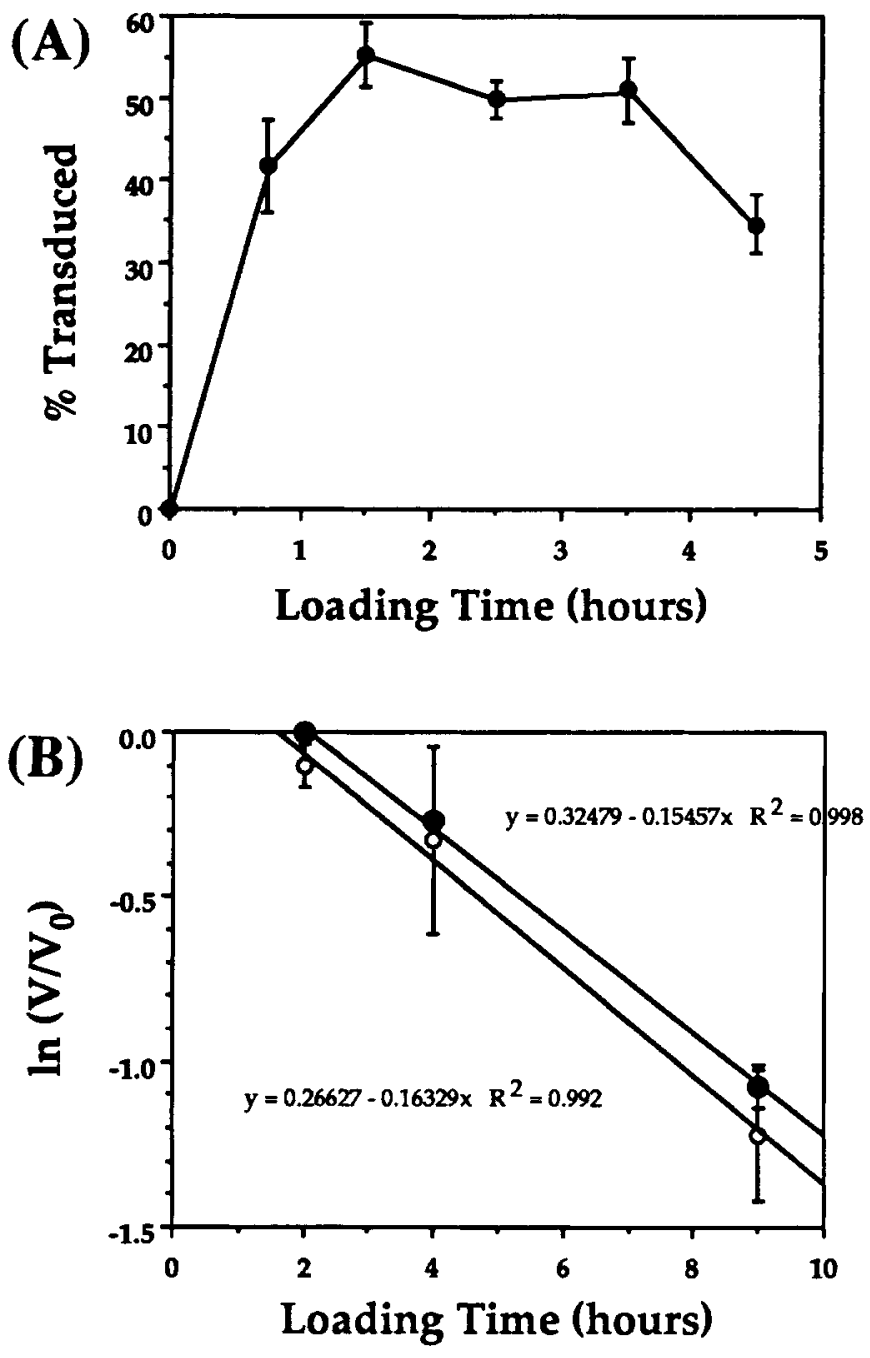

Figure 6. Virus activity on membrane after flow-through loading. (A) Viral activity is indicated by the scale of percentage of cells transduced (\% Transduced). Virus activity was measured by flow cytometry after flow through bare Transwell-COL ${ }^{\mathrm{TM}}$ membranes for the time period shown (= Loading time). Each datapoint represents the average of two independent measurements. (B) Viral decay rate on bare Transwell-COL ${ }^{\mathrm{m}}$ membranes after flowing through the membrane for an extended loading period of 2 to $9 \mathrm{~h}(\boldsymbol{\theta})$. This decay rate is compared with the decay of a static loading $(O)$, in which the same types of bare membranes were exposed to the same batch of virus solution for the same period of time, but in the static overlay method. $\mathrm{V}=$ virus activity at the loading time and $\mathrm{V}_{0}=$ initial virus activity just before loading. NIH/3T3 cells seeded onto tissue culture plates were used to measure virus activity. Each data-point represents the average of two independent samples. The half-life can be calculated from the slopes shown, $\sim 4.2$ and $\sim 4.5 \mathrm{~h}(\ln 2 / 0.16329=4.2$ and $\ln 2 /$ $0.15457=4.5$ ), for the flow-through and static-loaded viruses, respectively.

\section{Kinetics of Flow-Through Transductions Using Different Membrane Substrates}

The optimal flowrate shown in Figure 4 was for short transduction times of 3 to 4 hours. The efficacy of the time of flow was compared with the total time of virus exposure in static overlay transductions. Figure 7A shows the percentage of cells transduced as a function of transduction time. "Transduction time" is the total virus exposure time for the static method, and is the virus solution flow-through time for the flow-through method. The optimal time for transductions using flowthrough typically occurred within 3 to 4 hours of virus solution flow, with the number of transductions remaining constant thereafter (Fig. 7A). This optimal time was shorter than in static transductions, where peak numbers of gene transfer occurred consistently between 7 and $10 \mathrm{~h}$. The optimal time for static transductions has been shown to be approximately equal to the half-life of the virus. ${ }^{5}$

The effect of polybrene on flow-through transductions was examined using a range of concentration that was not toxic to the target cells (as measured by trypan blue exclusion and number of cells recovered at time of lac $Z$ expression assay). The level of polybrene may affect the interaction between the virus and target cell, but it is not expected to affect the fluid flow behavior through a given membrane. The effect of the membrane type, screen membrane versus depth membrane, was examined using the Transwell-clear ${ }^{\mathrm{TM}}$ and Transwell$\mathrm{COL}^{\mathrm{TM}}$ cell culture inserts, respectively. The two membranes' microscopic structures are shown in Figure 8. Transduction by flow through the Transwell- $\mathrm{COL}^{\mathrm{TM}}$ membrane could yield a significant percentage of cells transduced $(\sim 35 \%)$ even in the absence of polybrene (Fig. 7B). Flow through the Trans-clear ${ }^{\mathrm{TM}}$ membranes in the absence of polybrene resulted in no transductions, similar to the static method of delivery (Fig. 7B). In the presence of high concentrations of polybrene $(13.2 \mu \mathrm{g} /$ $\mathrm{ml}$ ), the number of transductions for flow through the Transwell-clear ${ }^{\mathrm{TM}}$ membrane continued to increase over $9 \mathrm{~h}$, and approached the plateau of the Transwell-COL ${ }^{\mathrm{TM}}$ membrane (Fig. 7C). Thus, the Transwell-clear ${ }^{\mathrm{TM}}$ membrane may reach saturation much later than the Transwell-COL ${ }^{\mathrm{TM}}$ membrane, although the flowrates, retrovirus solutions, and target cell densities were similar in both cases.

A comparison of the transductions yielded by flow through the different membrane types and the static method is shown as a function of polybrene concentrations in Figure 9, where an 8-h transduction time was used. Gene transfer by flow through the Transwell$\mathrm{COL}^{\mathrm{TM}}$ membrane was much less sensitive to the presence of polybrene than by either the static method or flow through the Transwell-clear ${ }^{\mathrm{TM}}$ membranes (Fig. 9). This figure also shows that flow through the Transwellclear $^{\mathrm{IM}}$ membranes could perform as well as flow through the Transwell-COL ${ }^{\mathrm{TM}}$ membranes at high polybrene levels.

The percentage of transduced cells yielded from flow through the Transwell-clear ${ }^{\mathrm{TM}}$ membranes continued to increase with polybrene levels up to $22 \mu \mathrm{g} / \mathrm{L}$, whereas the percentage from flow through the Transwell- $\mathrm{COL}^{\mathrm{TM}}$ increased up to only $2.2 \mu \mathrm{g} / \mathrm{ml}$ and plateaued thereafter. 
(A)

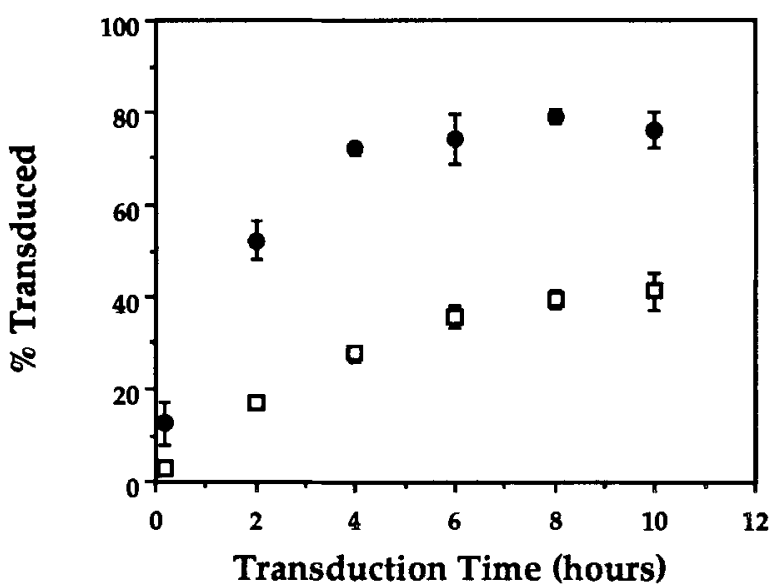

(B)

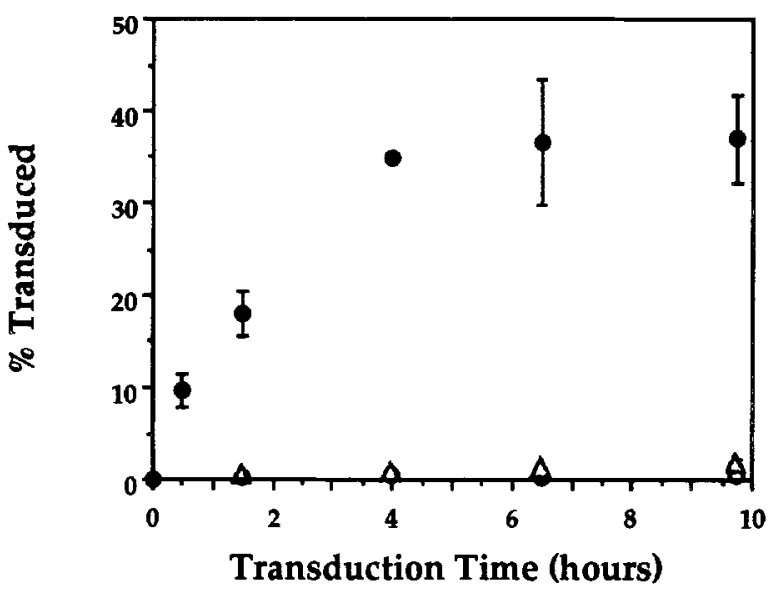

(C)

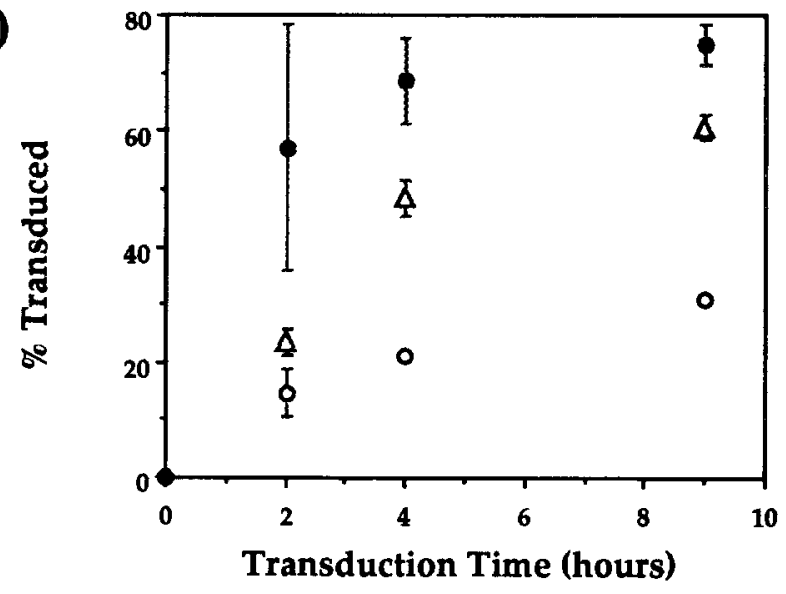

Figure 7. Flow-through vs. static transduction kinetics: effect of membrane type and polybrene level. Transduction efficiency (\% Transduced) as a function of transduction time. Transwell- $\mathrm{COL}^{\mathrm{TM}}(\boldsymbol{\bullet})$ and Transwell-clear ${ }^{\text {TM }}(\triangle)$ membranes were used for the flow-through and compared with static transductions $(O)$. NIH/3T3 cells were used as the target. Each datapoint represents the average of two independent samples. (A) $4.4 \mu \mathrm{g} / \mathrm{mL}$ polybrene was used in the virus solution (no Transwell-clear ${ }^{\text {th }}$ membrane data shown). (B) Absence of polybrene. (C) High level of polybrene $(13.2 \mu \mathrm{g} / \mathrm{mL})$.

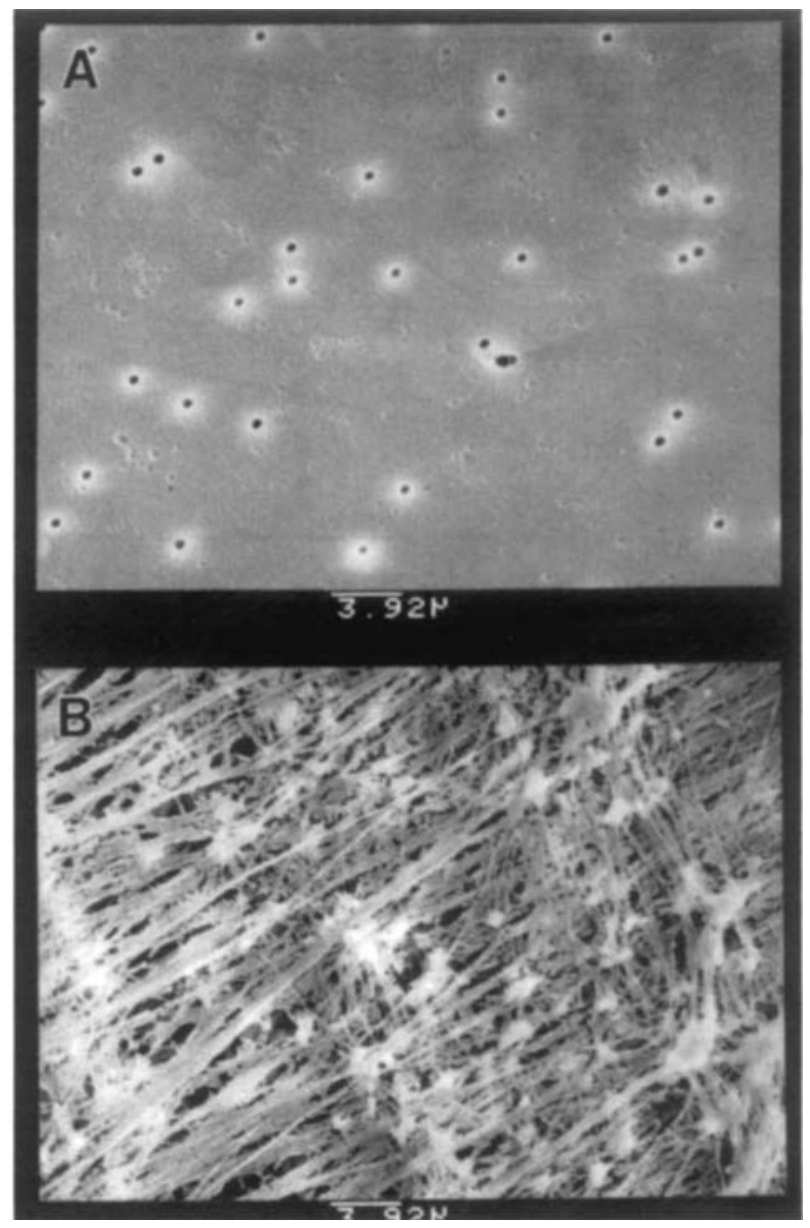

Figure 8. Membrane structure. SEM's of screen type membrane (polyester, Transwell-clear ${ }^{\mathrm{TW}}$ ) and depth type (collagen-coated Teflon mesh, Transwell-COL ${ }^{\mathrm{TM}}$ ). Both membranes have a pore size rating of $0.4 \mu \mathrm{m}$. The size bars indicate a length of $3.92 \mu \mathrm{m}$.

The maximal level of transduction was the same for both membranes. Thus, the sensitivity of flow-through transductions to polybrene was determined by the type of membrane used. Transwell-COL ${ }^{\mathrm{TM}}$ and Transwellclear $^{\mathrm{TM}}$ membranes could perform equivalently in the presence of polybrene; in polybrene's absence, transductions did not occur with flow through the negatively charged (tissue culture treated) screen membrane (Transwell-clear ${ }^{\mathrm{TM}}$ ). The success of the static overlay transductions depended on the presence of polybrene.

\section{DISCUSSION}

The limitations imposed by Brownian motion on retrovirus-mediated gene transfer can be overcome by implementing the flow-through transduction procedure. The kinetics of the flow-through procedure were investigated in the present study. The results show that: (1) the limitation of Brownian motion can be overcome using flowrates on the order of $0.1 \mathrm{~cm} / \mathrm{h}$ or greater; (2) the time profile of virus adsorption to the membrane 


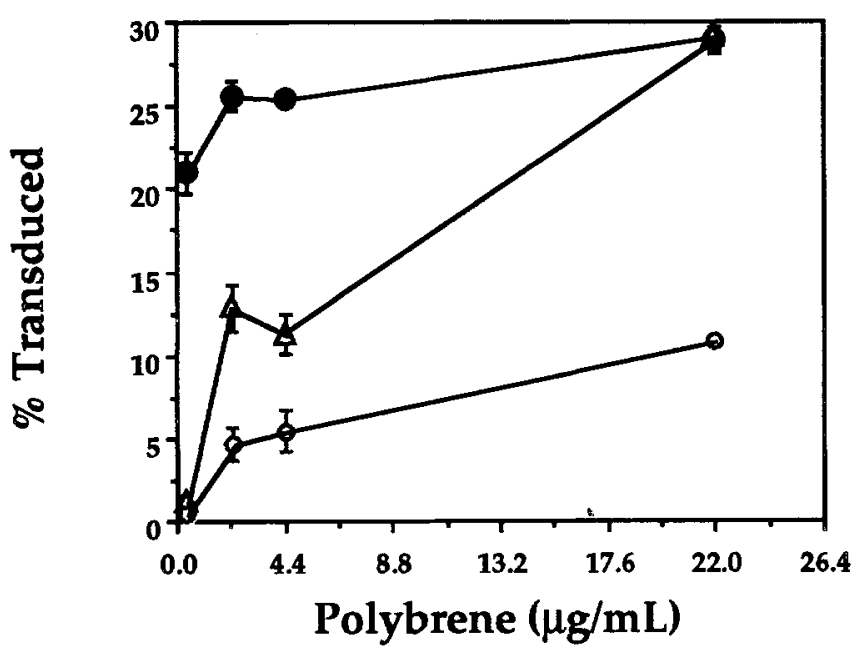

Figure 9. Flow-through vs. static transductions: effect of membrane type and polybrene level. Transduction efficiency (\% Transduced) as a function of polybrene level. Transwell-COL ${ }^{\mathrm{TM}}$ membranes $(\bullet)$ and Transwell-clear ${ }^{\mathrm{TM}}$ membranes $(\triangle)$ were used for the flow-through and compared against static transductions on Transwell-COL ${ }^{\mathrm{TM}} \mathrm{mem}-$ branes (O). NIH/3T3 cells were used as the target. An $8 \mathrm{~h}$ transduction period was used. Each datapoint represents the average of two independent samples.

shows a peak in the number of active viruses adsorbed after about 2 to $4 \mathrm{~h}$, and this maximum is consistent with the cumulative number of cell transductions obtained over time; and (3) the adsorption characteristics of the membrane play a key role in determining the transduction efficiencies achieved by the flow-through procedure.

To overcome the limitations imposed by Brownian motion, a sufficiently high fluid flow velocity must be attained so that the number of viruses encountering the membrane and the cell bed is controlled by fluid flow; for instance, the diffusional (Brownian) velocity must be exceeded by the net fluid flowrate. The data obtained suggests that fluid flowrates above approximately $0.1 \mathrm{~cm} / \mathrm{h}$ are sufficient to overcome Brownian motion. A priori one would estimate that the Brownian motion penetration distance of $\sim 500 \mu \mathrm{m}^{5}$ needs to be traveled by fluid flow minimally over about one half-life (on the order of 3.5 to $6.5 \mathrm{~h}$ ), yielding an estimate of about $0.01 \mathrm{~cm} / \mathrm{h}$. The flowrates at which the plateau was reached in the present study exceed, but are consistent with, this estimate. The extremely low flowrates of $0.01 \mathrm{~cm} / \mathrm{h}$ were not reached with the apparatus used in this study and the precise flowrate at which the transition from Brownian motion dominated delivery to convective dominated delivery could not be determined. In practice, however, all one needs is to exceed the effective diffusional velocities to obtain the potential benefits of the flow-through procedure without damaging the target cells.

The optimal time of transduction through the collagen-coated depth type membrane occurred at 3 to
$4 \mathrm{~h}$ after the inception of fluid flow with a (gravity) flowrate of approximately $0.2 \mathrm{~cm} / \mathrm{h}$. This optimal time also corresponded with the time $(4 \mathrm{~h})$ after which additional virus could no longer be deposited onto the membrane (Fig. 6A), and further measurements of membrane-associated virus activity showed that the virus was merely decaying with time (Fig. 6B). The correspondence in optimal times suggests the capacity of the membrane for adsorbing virus may determine the optimal time of flow-through transduction. It is likely that nonviral factors, such as serum components, were responsible for the membrane filling to capacity. Each membrane has available only a limited number of sites, and given the large number of proteins in the medium (10\% serum was used as the basal medium for the virus solution, as described in Material and Methods), many of the potential binding sites were almost certainly occupied by proteins.

If the serum, or nonviral protein concentration is decreased, then there should be an increase in the number of binding sites available to viruses, ${ }^{26,27}$ assuming the viral half-life remains the same and the target cell's susceptibility to transduction is unchanged. The period of maximal virus adsorption is consistent with the period of increasing transduction efficiency and suggests that at least a portion of the benefits of flow-through come by adsorbing the virus to the membrane, thus colocalizing the target cell and gene carrier such that their effective contact is significantly increased. The enhancement achieved by co-localization supports the hypothesis that the encounter between virus and target cell limits the efficiency of the gene transfer process. ${ }^{5}$ The benefits of the flow-through procedure can thus be obtained by selecting the appropriate flow velocities and membrane adsorption characteristics. For different applications using other gene carriers, the membranes should be selected or "tailor-made" for the viral vector to be adsorbed.

The adsorption characteristics of the membrane for a given viral vector will vary with membrane type and membrane treatment. Different membrane characteristics were found to influence the flow-through transduction efficiency. The total amounts of viral vector adsorbed by the depth membrane and the screen membrane after flow-through were expected to be different: the porosity and thickness of track-etched membranes are generally smaller than those of depth membranes, and the area available for particle capture on screen membranes is also less than that for depth membranes. However, it is the number of viral vectors captured on the surface of the membrane, where the target cells are found, that should contribute to the number of transductions gained by flow-through. In addition to serum level, retrovirus adsorption onto the membrane can be modulated by polybrene. Transduction conditions may be designed such that the numbers of gene transfer events using either the depth or screen membrane are equiva- 
lent. These experimental conditions may be independent of fluid flow behavior (e.g., transduction time and polybrene levels, as demonstrated by the trends shown in Fig. 7C and 9, respectively).

This equivalence in percentage of targets expressing the transferred gene suggests that, under the right circumstances, the number of viral vectors reaching the membrane surfaces can be the same, further supporting the conclusion that virus adsorption by the membrane is the key event leading to enhancements.

A model of the number of target cells transduced using the flow-through method can subsequently be formulated, once a membrane's adsorption kinetics and the virus uptake rate (by a given target cell type) have been defined. Using the Transwell-COL ${ }^{\mathrm{TM}}$ membrane, the rate of virus removal from solution by flow-through was measured to be exponential (Fig. 5). The surface viral concentration can thus be approximated with an exponential function during the adsorption period (approximately $4 \mathrm{~h}$ here), although only the viruses deposited onto the membrane surface are likely candidates for successful transduction. In addition to the membrane type, the rate of virus removal will likely depend on the virus solution polybrene level, the flow-through time, the virus solution flow velocity, and the serum (or nonviral protein) concentration. The effect of these factors on membrane adsorption and surface viral concentration should be further investigated. The rate of viral uptake can, to a first approximation, be described as being first order in the local (surface) viral concentration. However, the mechanism of retroviral internalization needs to also be defined with respect to virus concentration and surface receptor occupancy, before a model of virus uptake can be reasonably predictive.

Taken together, the results of the present study and our previous study ${ }^{5}$ show that Brownian motion limits the efficiency of retrovirus-mediated gene transfer and that this limitation can be overcome by using net convective flow through the target cell bed. Once a sufficient flow velocity to overcome random Brownian motion is implemented, the virus adsorption characteristics of the membrane are key in determining the number of increased gene transfer events. The characteristics of the membrane, therefore, become a key design consideration for the optimization of the flowthrough transduction procedure. Optimal virus adsorption characteristics, as well as the cell attachment and growth characteristics on the membrane, may have to be determined on a case-by-case basis, given specific viral vectors and target cell populations. The increase in gene transfer events by flow-through is not expected to be limited to retroviral gene carriers. Properly designed and operated flow-though transduction procedures are likely to lead to significantly enhanced gene transfer rates for both research and clinical applications.
We thank Oveta Fuller for helpful discussions, Bob Fish for constructing the membrane housings, and James Wilson for providing the retroviral packaging cell line used in this work. This research was funded by Aastrom Biosciences, Inc.

\section{References}

1. Ausubel, F. M. 1993. Introduction of DNA into mammalian cells. In: F. M. Ausubel, R. Brent, R. E. Kingston, D. D. Moore, J. G. Seidman, J. A. Smith, and K. Struhl (eds.) Current protocols in molecular biology. John Wiley \& Sons, New York.

2. Aubin, R. A., Weinfeld, M., Mirzayans, R., Paterson, M. C. 1994. Polybrene/DMSO-assisted gene transfer. Mol. Biotechnol. 1: 29-28.

3. Belmont, J. W., MacGregor, G. R., Wager-Smith, K., Fletcher, F. A., Moore, K. A., Hawkins, D., Villalon, D., Chang, S. M.-W., Caskey, C. T. 1988. Expression of human adenosine deaminase in murine hematopoietic cells. Mol. Cell. Biol. 8: 5116-5125.

4. Bodine, D. M., McDonagh, K. T., Brandt, S. J., Ney, P. A., Agricoal, B., Byrne, E., Neinhuis, A. W. 1990. Development of a higher-titer retrovirus producer cell line capable of gene transfer into rhesus monkey hematopoietic stem cells Proc. Natl. Acad. Sci. USA 87: $3738-3742$.

5. Chuck, A. S. 1995. Directed retroviral motion as a means of enhancing gene transfer for gene therapy, Ph.D. thesis, The University of Michigan, Ann Arbor, MI.

6. Coelen, R. J., Jose, D. G., and May, J. T. 1983. The effect of hexadimethrine bromide (Polybrene) on the infection of the primate retroviruses SSV1/SSAV1 and BaEV. Arch. Virol. 75: 307-311.

7. Cornetta, K., Anderson, W. F. 1989. Protamine sulfate as an effective alternative to polybrene in retroviral-mediated gene-transfer: implications for human gene therapy. J. Virol. Meth. 23: 11871194.

8. Crystal, R. G. 1995. Transfer of genes to humans: early lessons and obstacles to success. Science 270: 404-410.

9. Cussler, E. L. 1984. p. 118. Diffusion: mass transfer in fluid systems. Cambridge University Press, New York.

10. Danos, O., Mulligan, R. C. 1988. Safe and efficient generation of recombinant retroviruses with amphotropic and ecotropic host ranges. Proc. Natl. Acad. Sci USA 85: 6460-6464.

11. Dubois-Dalcq, M., Holmes, K. V., Rentier, B. 1984. pp. 149-170. Assembly of enveloped RNA viruses. Springer Verlag, New York.

12. Einstein, A. 1905. Annalen der Physik 17: 549-560.

13. Haywood, A. M. 1994. Virus receptors: binding, adhesion strengthening, and changes in viral structure. J. Virol. 68: 1-5.

14. Helenius, A., Kartenbeck, J., Simons, K., and Fries, E. 1980. On the entry of Semliki Forest Virus into BHK-21 cells. J. Cell Biol. 84: $404-420$.

15. Kotani, H., Newton, P. B. III, Zhang, S., Chiang, Y. L., Otto, E., Weaver, L., Blaese, R. M., Anderson, W. F., McGarrity, G. J. 1994. Improved methods of retroviral vector transduction and production for gene therapy. Hum. Gene Ther. 5: 19-28.

16. Layne, S. P., Spouge, J. L., Dembo, M. 1989. Quantifying the transductivity of human immunodeficiency virus. Proc. Natl. Acad. Sci. USA 86: 4644-4648.

17. Levin, J. G., Rosenak, M. J. 1976. Proc. Natl. Acad. Sci USA 73: $1154-1158$.

18. Lowy, D. R. 1985. p. 237. In: B. N. Fields et al. (eds.), Virology. Raven Press, New York.

19. Lynch, C. M., Miller, A. D. 1991. Production of high-titer helper virus-free retroviral vectors by cocultivation of packaging cells with different host ranges. J. Virol. 65: 3887-3890.

20. Marsh, M. 1984. The entry of enveloped viruses into cells by endocytosis. Biochem. J. 218: 1-10.

21. McClain, D. S., Fuller, A. O. 1994. Cell-specific kinetics and efficiency of herpes simplex virus type 1 entry are determined by two distinct phases of attachment. Virology 198: 690-702. 
22. Miller, A. D. 1992. Retroviral vectors. Curr. Top. Microbiol. Immunol. 158: 1-24.

23. Mulligan, R. C. 1993. The basic science of gene therapy. Science 260: $926-932$

24. Paul, R. W., Morris, D., Hess, B. W., Dunn, J., Overell, R. W. 1993. Increased viral titer through concentration of viral harvests from retroviral packaging cell lines. Hum. Gene Ther. 4: 609615.

25. Sanes, J. R., Rubenstein, J. L. R., Nicolas, J.-F. 1986. Use of a recombinant retrovirus to study post-implantation cell lineage in mouse embryos. EMBO J. 5: 3133-3142.
26. Ver, B. A., Melnick, J. L., Wallis, C. 1968. Efficient filtration and sizing of viruses with membrane filters. J. Virol. 2: 21-25.

27. Wallis, C., Melnick, J. L. 1967. Concentration of enteroviruses on membrane filters. J. Virol. 1: 472-477.

28. Wickham, T. J., Granados, R. R., Wood, H. A., Hammer, D. A., Shuler, M. L. 1990. General analysis of receptor-mediated viral attachment to cell surfaces. Biophys. J. 58: 1501-1516.

29. Wilson, J. M., Jefferson, D. M., Chowdhury, J. R., Novikoff, P. M., Johnston, D. E., Mulligan, R. C. 1988. Retrovirus-mediated transduction of adult hepatocytes Proc. Natl. Acad. Sci. USA 85: 30143018. 